\title{
Evaluation of phosphate in fertilizers by means of the alkaline ammonium citrate extraction according to Petermann
}

\section{R. Boxma}

Institute for Soil Fertility, Haren (Gr.), the Netherlands

Accepted: 8 February 1977

Key words: available phosphate, fertilizers, quality control

\section{Summary}

The phosphate extraction with alkaline ammonium citrate solution for the control of phosphate in fertilizers was subjected to a critical examination. The contribution of inferior phosphate forms such as tricalcium phosphates and apatites to the available $\mathrm{P}_{2} \mathrm{O}_{5}$ percentage can be excluded to a great extent by using a narrow sample solvent ratio.

However, the dissolution rate of dicalcium phosphate in alkaline ammonium citrate solution puts limits on the narrowing of the ratio.

The dissolution rate of dicalcium phosphate can be increased, if instead of intermittently manual shaking mechanical shaking is applied.

Extraction of $1.0 \mathrm{~g}$ sample with $200 \mathrm{ml}$ of alkaline ammonium citrate solution at $65{ }^{\circ} \mathrm{C}$ under mechanical shaking for 1.5 hours is preferred to other methods for quality control of phosphate in fertilizers. The extraction method with neutral ammonium citrate solution is not reliable, because this method makes little or no distinction between high quality and low quality fertilizers.

\section{Introduction}

Nearly every country has regulations governing the marketing of fertilizers. These regulations include an analytical examination of the material for determining its nutrient content. Up to now the quality of the phosphate in fertilizers has been controlled in the Netherlands by the extraction with a neutral ammonium citrate solution (NAC). Several critisms can be made regarding this method, and therefore the question can be raised if the NAC method adequately characterizes the fertilizers that are currently being used.

Hignett \& Brabson (1961) examined the water-insoluble phosphate in mixtures of dicalcium phosphate and basic calcium phosphate, using NAC and alkaline ammonium citrate (AAC) extractions. They found that neutral ammonium citrate does not only dissolve the dicalcium phosphate but also for a great part the basic calcium phosphate (predominantly hydroxyapatite). In alkaline ammonium citrate solution, 
however, dicalcium phosphate was almost completely soluble, but the basic phosphate was practically insoluble.

Wright et al. (1965) demonstrated that ammoniation of ordinary superphosphate decreased the agronomic phosphate effectiveness of the fertilizer and the loss of efficiency became greater as the degree of ammoniation increased. This loss of effectiveness was not reflected in the NAC method. However, the phosphate values obtained by the AAC were highly correlated with crop response. Therefore the NAC method is not a reliable basis for quality control and for protection of the customer, because calcium phosphates more basic than dicalcium phosphate are also extracted by the NAC solution.

Several workers have found that the ratio of sample weight to solvent volume has marked effects on the percentage of the phosphate dissolved by the neutral and alkaline citrate solutions.

Percentages of water-insoluble $\mathrm{P}_{2} \mathrm{O}_{5}$ which dissolved in both extractants increased with decrease in sample size. They recommended standardization of the extraction procedures by using a constant ratio between the citrate volume and the amount of water-insoluble $\mathrm{P}_{2} \mathrm{O}_{5}$ in the fertilizer.

The present work was designed to test the critical conditions of the alkaline ammonium citrate extraction for the separation of dicalcium phosphate and basic calcium phosphates in fertilizers and to compare the results with those of the neutral ammonium citrate extraction for a representative group of fertilizers.

\section{Experimental}

\section{Extraction with neutral ammonium citrate solution}

The NAC solution was prepared by dissolving $370 \mathrm{~g}$ of citric acid in $1500 \mathrm{ml}$ water. After addition of $345 \mathrm{ml}$ ammonia $\left(28-29 \% \mathrm{NH}_{3}\right)$ the solution was cooled and adjusted with diluted ammonia or citric acid solution exactly to $\mathrm{pH} 7.0$. Finally the solution was diluted with water to a specific gravity of 1.09 (volume will be about 2 litres).

Fertilizer samples of 0.5 and $1.0 \mathrm{~g}$ were extracted with $200 \mathrm{ml} \mathrm{NAC}$ solution by shaking for 3 hours on a mechanical shaker at room temperature followed by warming for 1 hour at $65^{\circ} \mathrm{C}$ with intermittently manual shaking. After cooling the mixture was made up to $500 \mathrm{ml}$ with water and filtered. In the filtrate phosphorus was determined by the quinoline method (Lang, 1967).

\section{Extraction with alkaline ammonium citrate solution according to Petermann}

Exactly $173 \mathrm{~g}$ of citric acid was dissolved in $500 \mathrm{ml}$ water. While the solution was cooled, $224.5 \mathrm{ml}$ ammonia containing $51.07 \mathrm{~g} \mathrm{NH}_{3}$ were added in small quantities. After dilution to 1 litre the $\mathrm{pH}$ of the solution should be 9.4-9.7 and the nitrogen content $42 \mathrm{~g} \mathrm{~N}$ per litre. Samples of fertilizers were extracted with $200 \mathrm{ml}$ of this solution. Besides the sample size also the mode of agitation, the temperature and the shaking time may have influence on the extraction of phosphate with the AAC solution. These extraction conditions were investigated in order to find the most reliable extraction procedure. 
R. BOXMA

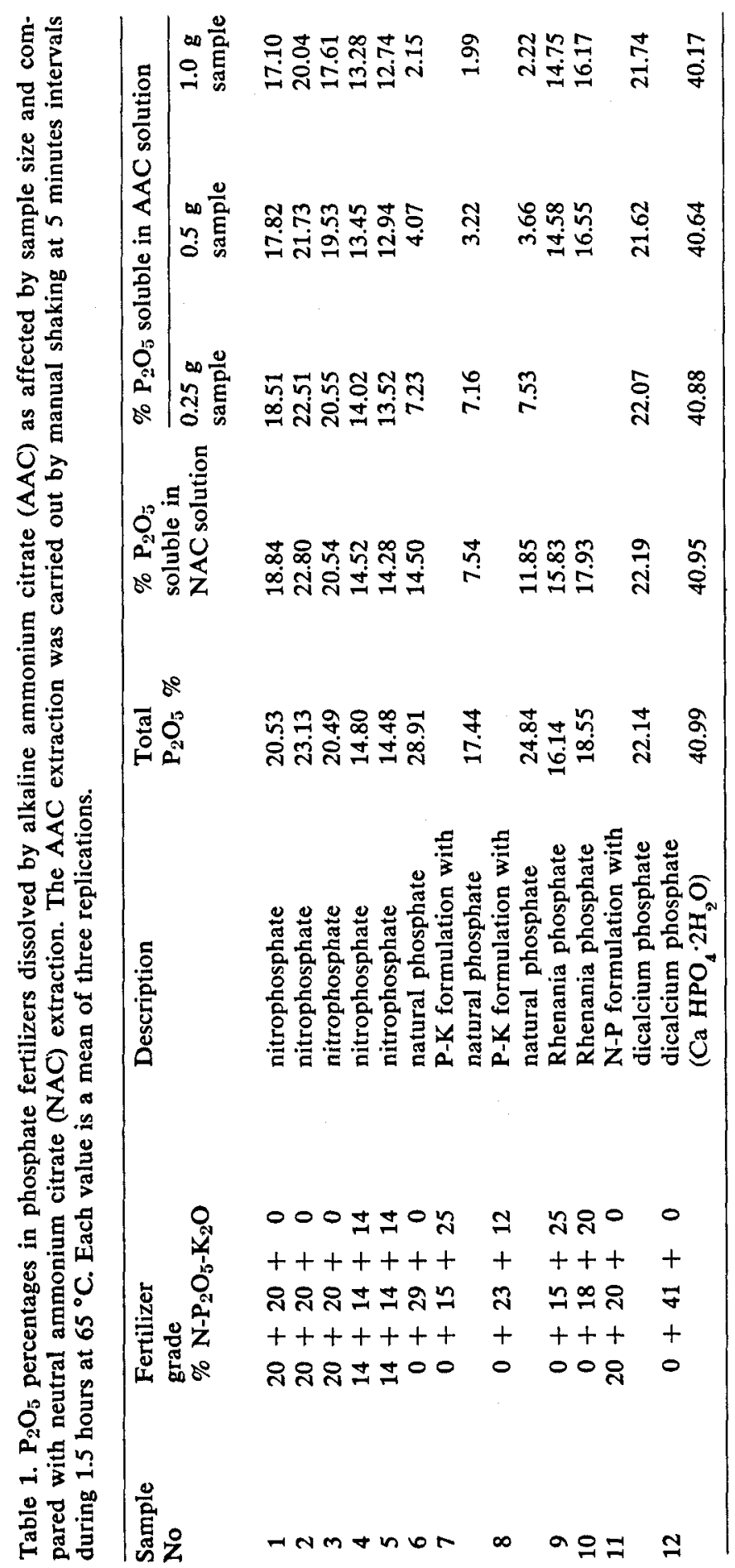




\section{Effects of the sample size and mode of agitation}

Extractions with different sample weights and a shaking time of 1.5 hours were carried out at $65^{\circ} \mathrm{C}$. Manual shaking at 5 minutes intervals was compared with continuously mechanical shaking.

\section{Effect of the extraction temperature}

Samples of $1.0 \mathrm{~g}$ were extracted at 20 and $65^{\circ} \mathrm{C}$ by means of mechanical shaking for 1.5 hours.

\section{Effect of the shaking time}

Samples of $0.5 \mathrm{~g}$ were shaken at $65^{\circ} \mathrm{C}$ for $1,1.5$ and 3 hours with a mechanical shaker.

After the extractions phosphorus was analyzed on the same way as described in the section 'Extraction with neutral ammonium citrate solution'.

Total $\mathrm{P}_{2} \mathrm{O}_{5}$ was determined in the fertilizers by boiling with a mixture of $\mathrm{H}_{2} \mathrm{SO}_{4}$ and $\mathrm{HNO}_{3}$. In the digest $\mathrm{P}_{2} \mathrm{O}_{5}$ was estimated according to the quinoline method (Lang, 1967).

\section{Materials}

A great number of mixed fertilizers (nitrophosphates and Rhenania phosphates) was used. Nitrophosphates are manufactured by decomposition of phosphate rock with nitric acid.

Also P-K formulations were made from natural ground phosphate, which is composed of fluorapatite. Single compounds such as dicalcium phosphate and tricalcium phosphate were also involved in this study. The fertilizers were ground to pass a $0.5 \mathrm{~mm}$ sieve.

\section{Results}

The data from Table 1 show, that the AAC extractions give lower percentages of $\mathrm{P}_{2} \mathrm{O}_{5}$ than the NAC extractions if sample weights of $1.0 \mathrm{~g}$ are used. With decrease in size of sample from 1.0 to $0.25 \mathrm{~g}$ the percentage of $\mathrm{P}_{2} \mathrm{O}_{5}$, that was soluble in AAC solution increases in the most fertilizers.

Also it appears, that AAC dissolves little phosphate from fertilizers composed of fluorpatite (Nos 6, 7 and 8). In connection with the increase in dissolved percentage of $\mathrm{P}_{2} \mathrm{O}_{5}$ with decrease in size of sample it is of interest to note, that the dissolved amounts of $\mathrm{P}_{2} \mathrm{O}_{5}$ by weight of these fertilizers are not significantly influenced by the size of the sample. Although the fertilizers 6,7 and 8 vary in total phosphate content their AAC values show mutual little differentiation. These results indicate, that only a limited small amount of phosphate from fluorapatite can be dissolved in the AAC solution.

The higher $\mathrm{P}_{2} \mathrm{O}_{5}$ percentages of the nitrophosphates found by reduction of the sample size may have two causes. Besides water-soluble phosphate and dicalcium phosphate the fertilizers may contain a small amount of basic phosphates, resulting 
R. BOXMA

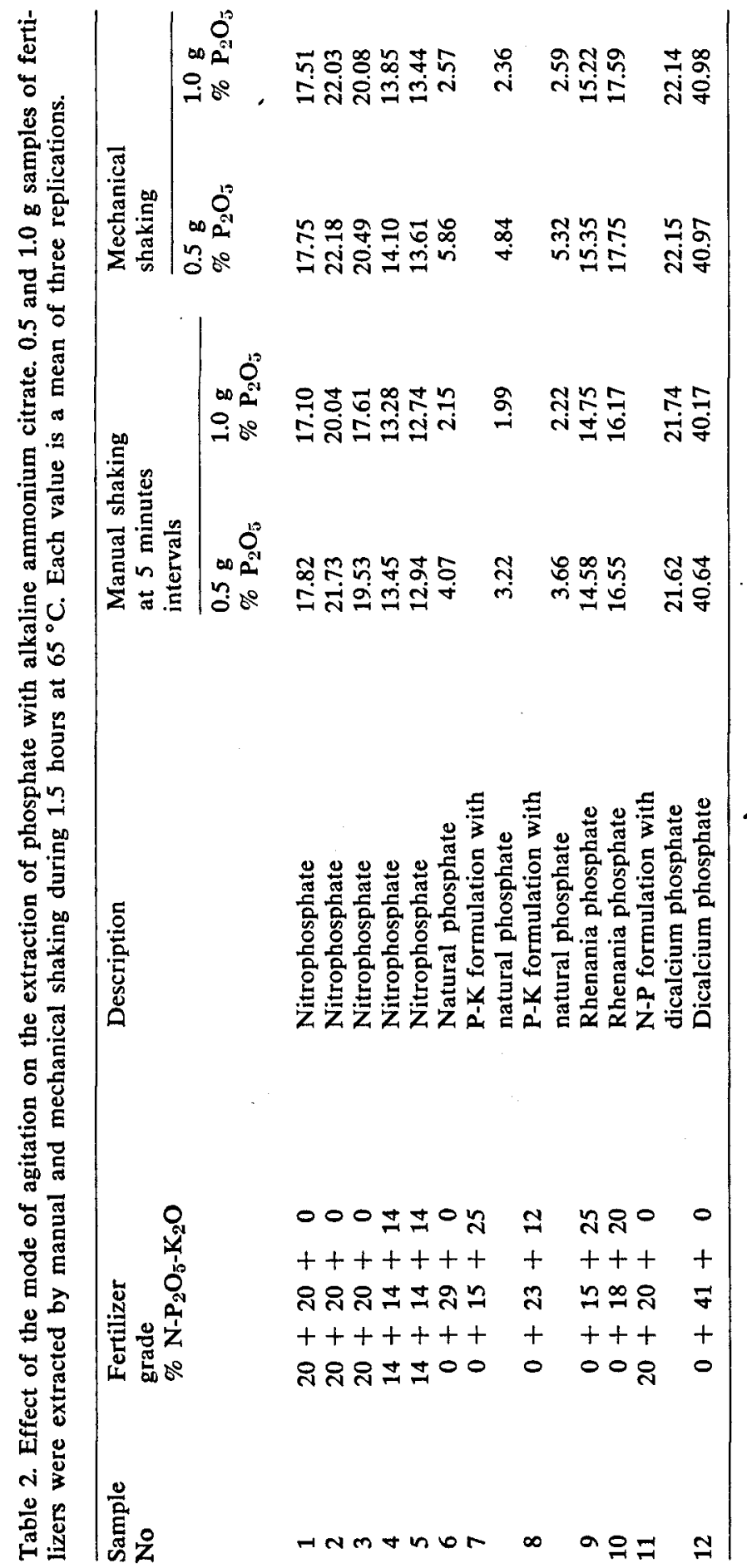


in a higher contribution of these phosphates to the $\mathrm{P}_{2} \mathrm{O}_{5}$ percentages of the lower sample weights. The second explanation for the increase of the $\mathrm{P}_{2} \mathrm{O}_{3}$ percentage with a decrease of the sample size may be a low dissolution rate of dicalcium phosphate in the AAC solution due to an ineffective mode of agitation. Indeed, too low $\mathrm{P}_{2} \mathrm{O}_{5}$ contents were found with samples of 1.0 and $0.5 \mathrm{~g}$ of the fertilizers Nos 11 and 12 , only containing dicalcium phosphate.

Generally, more $\mathrm{P}_{2} \mathrm{O}_{5}$ is extracted from the fertilizers by continuous mechanical shaking than by manual shaking at 5 -minute intervals (Table 2). The results also demonstrate, that under this mode of agitation dicalcium phosphate both at sample sizes of 0.5 and $1.0 \mathrm{~g}$ dissolves completely in the AAC solution. With respect to the nitrophosphates it can be remarked that the differences between the $\mathrm{P}_{2} \mathrm{O}_{5}$ contents samples of 0.5 and $1.0 \mathrm{~g}$ have been reduced. However, distinctly small differences between samples of 0.5 and $1.0 \mathrm{~g}$ still remain; these differences must be attributed to the presence of basic phosphates in the fertilizers, of which their contribution to the $\mathrm{P}_{2} \mathrm{O}_{5}$ content depends on the sample size.

From a second series of nitrophosphates it appears that the differences in $\mathrm{P}_{2} \mathrm{O}_{5}$ contents between samples of 0.5 and $1.0 \mathrm{~g}$ are small, whereas no differences are found between samples of 0.25 and $0.5 \mathrm{~g}$ (Table 3 ). The results indicate that these fertilizers contain small amounts of basic calcium phosphates. It is obvious that in the small samples the basic calcium phosphates, sparingly soluble in AAC solution, dissolve completely in $200 \mathrm{ml}$ of the AAC solution, but in the samples of $1.0 \mathrm{~g}$ only a fraction of these components dissolves because a condition close to saturation is reached.

For studying the effect of the quantity of basic calcium phosphates on the percentage of $\mathrm{P}_{2} \mathrm{O}_{5}$, soluble in AAC solution, the solubility of tricalcium phosphate was investigated. In view of its solubility in AAC this basic phosphate mainly consists of $\alpha$-tricalcium phosphate (Schmitt, 1969).

Table 3. Effect of the sample size on the extraction of phosphate with alkaline ammonium citrate. $0.25 \mathrm{~g} ; 0.5 \mathrm{~g}$ and $1.0 \mathrm{~g}$ samples of fertilizers were extracted by mechanical shaking during 1.5 hours at $65^{\circ} \mathrm{C}$. Each value is a mean of three replications.

\begin{tabular}{|c|c|c|c|c|c|c|}
\hline \multirow[t]{2}{*}{$\begin{array}{l}\text { Sample } \\
\text { No }\end{array}$} & \multirow{2}{*}{$\begin{array}{l}\text { Fertilizer } \\
\text { grade } \\
\% \mathrm{~N}-\mathrm{P}_{2} \mathrm{O}_{5}-\mathrm{K}_{2} \mathrm{O}\end{array}$} & \multirow[t]{2}{*}{ Description } & \multirow[t]{2}{*}{$\begin{array}{l}\text { Total } \\
\mathbf{P}_{2} \mathrm{O}_{5} \%\end{array}$} & \multicolumn{3}{|c|}{$\begin{array}{l}\% \mathrm{P}_{2} \mathrm{O}_{5} \text { soluble } \\
\text { in } \mathrm{AAC} \text { solution }\end{array}$} \\
\hline & & & & $\begin{array}{l}0.25 \mathrm{~g} \\
\text { sample }\end{array}$ & $\begin{array}{l}0.5 \mathrm{~g} \\
\text { sample }\end{array}$ & $\begin{array}{l}1.0 \mathrm{~g} \\
\text { sample }\end{array}$ \\
\hline 13 & $14+14+14$ & nitrophosphate & 14.08 & 13.79 & 13.89 & 13.59 \\
\hline 14 & $14+14+14$ & nitrophosphate & 14.43 & 13.78 & 13.77 & 13.37 \\
\hline 15 & $14+14+14$ & nitrophosphate & 14.18 & 13.66 & 13.68 & 13.45 \\
\hline 16 & $20+20+0$ & nitrophosphate & 20.05 & 19.81 & 19.78 & 19.58 \\
\hline 17 & $20+20+$ & nitrophosphate & 20.39 & 19.89 & 20.04 & 19.85 \\
\hline 18 & $20+20+$ & nitrophosphate & 20.23 & 20.00 & 19.93 & 19.79 \\
\hline 19 & $20+20+$ & nitrophosphate & 20.29 & 20.15 & 20.09 & 19.98 \\
\hline 20 & $20+20+0$ & nitrophosphate & 20.19 & 20.14 & 20.15 & 20.00 \\
\hline
\end{tabular}


R. BOXMA

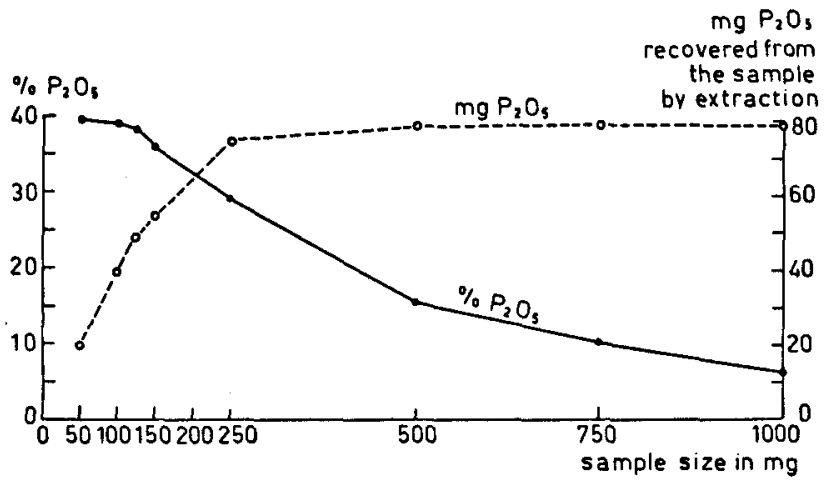

Fig. 1. Relationship between $\% \mathrm{P}_{2} \mathrm{O}_{5}$ and $\mathrm{mg} \mathrm{P}_{2} \mathrm{O}_{5}$ dependent on sample size, dissolved by alkaline ammonium citrate solution from tricalcium phosphate.

Fig. 1 illustrates the wide divergency of the percentages of $\mathrm{P}_{2} \mathrm{O}_{5}$, soluble in AAC between the different sample sizes of the tricalcium phosphate. The course of this curve can be explained from the solubility of the tricalcium phosphate. In the sample size range from 50 to $125 \mathrm{mg}$ the dissolved amounts of $\mathrm{P}_{2} \mathrm{O}_{5}$ increase proportionally with the sample weight, and the percentage of $\mathrm{P}_{2} \mathrm{O}_{5}$ are practically equal. Above a sample weight of $125 \mathrm{mg}$ the slope of the solubility line decreases, resulting in lower percentages of $\mathrm{P}_{2} \mathrm{O}_{5}$. Finally, at sample weights of $250 \mathrm{mg}$ and more a condition of saturation is reached and the percentage of $\mathrm{P}_{2} \mathrm{O}_{5}$ shows a drastic fall, when the sample weight increases.

Table 4. Solubility of phosphates in alkaline ammonium citrate at 20 and $65^{\circ} \mathrm{C}$. Samples of $1 \mathrm{~g}$ were extracted by means of mechanical shaking during 1.5 hours. Each value is a mean of three replications.

\begin{tabular}{|c|c|c|c|c|}
\hline $\begin{array}{l}\text { Sample } \\
\text { No }\end{array}$ & $\begin{array}{l}\text { Fertilizer } \\
\text { grade } \\
\% \mathrm{~N}-\mathrm{P}_{2} \mathrm{O}_{5}-\mathrm{K}_{2} \mathrm{O}\end{array}$ & Description & $\begin{array}{l}20^{\circ} \mathrm{C} \\
\% \mathrm{P}_{2} \mathrm{O}_{5}\end{array}$ & $\begin{array}{l}65^{\circ} \mathrm{C} \\
\% \mathrm{P}_{2} \mathrm{O}_{5}\end{array}$ \\
\hline 1 & $20+20+0$ & nitrophosphate & 16.96 & 17.51 \\
\hline 2 & $20+20+0$ & nitrophosphate & 21.85 & 22.03 \\
\hline 3 & $20+20+0$ & nitrophosphate & 19.51 & 20.08 \\
\hline 4 & $14+14+14$ & nitrophosphate & 13.48 & 13.85 \\
\hline 5 & $14+14+14$ & nitrophosphate & 12.92 & 13.44 \\
\hline 6 & $0+29+0$ & natural phosphate & 0.91 & 2.57 \\
\hline 7 & $0+15+25$ & $\begin{array}{l}\text { P-K formulation with } \\
\text { natural phosphate }\end{array}$ & 0.85 & 2.36 \\
\hline 8 & $0+23+12$ & $\begin{array}{l}\text { P-K formulation with } \\
\text { natural phosphate }\end{array}$ & 0.89 & 2.59 \\
\hline 11 & $20+20+0$ & $\begin{array}{l}\text { N-P formulation with } \\
\text { dicalcium phosphate }\end{array}$ & 21.98 & 22.14 \\
\hline 12 & $0+41+0$ & $\begin{array}{l}\text { dicalcium phosphate } \\
\left(\mathrm{CaHPO} \mathrm{O}_{4} \cdot 2 \mathrm{H}_{2} \mathrm{O}\right)\end{array}$ & 40.22 & 40.98 \\
\hline
\end{tabular}




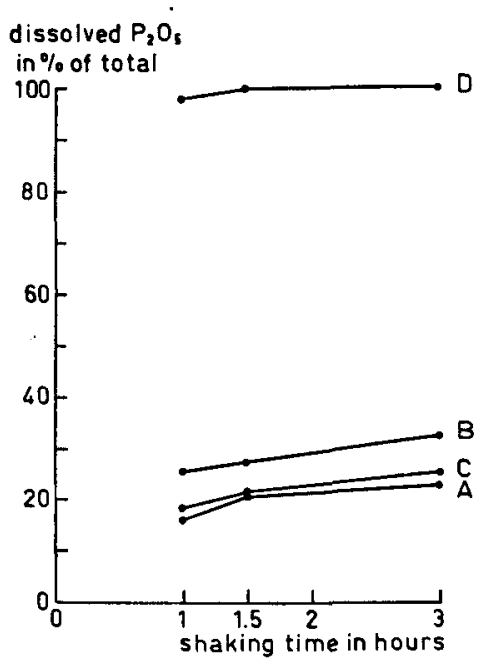

Fig. 2. Effect of the shaking time on the dissolution of phosphate from fertilizers in alkaline ammonium citrate solution. (A) Natural phosphate $(0+29+0)$; (B) P-K formulation with natural phosphate $(0+15+25)$; (C) P-K formulation with natural phosphate $(0+23+12)$; (D) N-P formulation with dicalcium phosphate $(20+20$ $+0)$.

Table 4 demonstrates that at $65^{\circ} \mathrm{C}$ more phosphate from the fertilizers is extracted by AAC than at $20^{\circ} \mathrm{C}$. Although at $20^{\circ} \mathrm{C}$ the solubility of phosphate from fluorapatite is lower, the extraction temperature of $65^{\circ} \mathrm{C}$ must be maintained, because dicalcium phosphate dissolves insufficiently at $20^{\circ} \mathrm{C}$.

Since the solubility of phosphate from fluorapatite increases with the duration of the extraction, the shaking time must be chosen as short as possible. However, a shaking time of 1.5 hours is necessary to be sure that dicalcium phosphate is complete dissolved (Fig. 2).

\section{Discussion}

Among the conditions specified in the AAC extraction the sample weight is the most critical one. If phosphate fertilizers contain besides water-soluble $\mathrm{P}_{2} \mathrm{O}_{5}$ and dicalcium phosphate also more basic calcium phosphates, this last fraction will contribute more or less to the available $\mathrm{P}_{2} \mathrm{O}_{5}$ content, depending on its solubility in AAC and the used sample size. In consequence of this, small sizes may lead to an overestimation of the quality of some fertilizers. Therefore for minimizing this effect it is necessary to avoid the use of small sample sizes. If, however, the extraction is carried out with sample weights of $1.0 \mathrm{~g}$ and $200 \mathrm{ml}$ of AAC solution, the method is suitable to be adopted for guarantee and quality control. A widening of this sample solvent ratio must be dissuaded, because in a larger volume of citrate solution greater amounts of basic calcium phosphates are dissolved.

Some agronomists recommend to standardize the AAC extraction by using sample weights, containing the same amounts of water-insoluble phosphor. This idea may solve the problem, provided that the adjusted sample weights contain enough basic calcium phosphates to minimize their effect. Moreover the estimated amounts of water-insoluble phosphate must be free from the weakly soluble dicalcium phos- 
phate to be sure that from the calculated sample weights equal amounts of basic calcium phosphates are extracted.

Mechanical shaking instead of manual shaking is necessary to guarantee a sufficient dissolution rate of dicalcium phosphate during the extraction. Because the kind and the specifications of the extraction method vary from country to country it is highly desirable to come to a uniform procedure.

From the findings in this paper it is clear, that an extraction of $1.0 \mathrm{~g}$ sample with $200 \mathrm{ml}$ of AAC solution at $65^{\circ} \mathrm{C}$ under mechanical shaking during 1.5 hours gives the most reliable results for estimating the sum of water-soluble $\mathrm{P}_{2} \mathrm{O}_{5}$ and $\mathrm{P}_{2} \mathrm{O}_{5}$ from dicalcium phosphate in fertilizers.

\section{References}

Hignett, T. P. \& J. A. Brabson, 1961. Evaluation of water-insoluble phosphorus in fertilizers by extraction with alkaline ammonium citrate solutions. J. agric. Fd Chem. 9: 272-276.

Lang, K., 1967. Die gravimetrische Phosphatbestimmung nach der Chinolinmethode und ihre Anwendung bei Düngemitteln. Landw. Forsch. 20: 128-136.

Schmitt, L., 1969. Über die Beziehungen zwischen chemischer Löslichkeit und pflanzenphysiologischer Wirkung verschiedener Phosphatformen. I. Mitteilung. Landw. Forsch. 22: 109-115.

Wright, B. C., B. C. Murphy \& J. W. Gilliam, 1965. Relative availability of phosphorus in fertilizers varying in solubility of the phosphorus. Proc. Soil Sci. Soc. Am. 29: 423-426. 